\title{
Is there a link between pre-existing antibodies acquired due to childhood vaccinations or past infections and COVID-19? A case control study
}

\author{
Bilge Sumbul $^{1}$, Hilmi Erdem Sumbul ${ }^{2}$, Ramazan Azim Okyay ${ }^{3}$, Erdinç Gülümsek $^{2}$, Ahmet Riza Şahin $^{4}$, Baris Boral \\ ${ }^{5}$, Burhan Fatih Koçyiğitt ${ }^{\text {Corresp., } 6}{ }^{\text {, Mostafa Alfishawy }}{ }^{7}$, Jeffrey Gold ${ }^{8}$, ALİ Muhittin Tasdogan ${ }^{9}$ \\ ${ }^{1}$ Department of Medical Microbiology, Bezmialem Vakıf University, Faculty of Medicine, Istanbul, Turkey \\ 2 Department of Internal Medicine, University of Health Sciences, Adana Health Practice and Research Center, Adana, Turkey \\ 3 Department of Public Health, Kahramanmaraş Sütçü Imam University, Faculty of Medicine, Kahramanmaraş, Turkey \\ 4 Department of Infectious Diseases and Clinical Microbiology, Kahramanmaraş Sütçü İmam University, Faculty of Medicine, Kahramanmaraş, Turkey \\ 5 Department of Microbiology, University of Health Sciences, Adana Health Practice and Research Center, Adana, Turkey \\ 6 Department of Physical Medicine and Rehabilitation, Kahramanmaraş Sütçü İmam University, Faculty of Medicine, Kahramanmaraş, Turkey \\ 7 Infectious Diseases Consultants and Academic Researchers of Egypt (IDCARE), Cairo, Egypt \\ 8 World Organization, Watkinsville, Georgia, USA \\ 9 Department of Anesthesiology and Reanimation, Hasan Kalyoncu University, Faculty of Health Sciences, Gaziantep, Turkey \\ Corresponding Author: Burhan Fatih Koçyiğit \\ Email address: bfatihkocyigit@ksu.edu.tr
}

Background: There is growing evidence indicating that children are less affected from COVID-19. Some authors speculate that childhood vaccinations may provide some crossprotection against COVID-19. In this study, our aim was to compare the circulating antibody titers for multiple childhood vaccine antigens, as an indicator of the state of immune memory between patients with COVID-19 and healthy controls, with a specific aim to identify the association between disease severity and antibody titrations which may indicate a protective function related to vaccine or disease induced memory. Methods: This study is a case-control study including 53 patients with COVID-19 and 40 healthy volunteers. COVID-19 severity was divided into three groups: asymptomatic, mild and severe. We measured the same set of antibody titers for vaccine antigens, and a set of biochemical and infection markers, in both the case and control groups. Results: Rubella $(p=0.003)$, pneumococcus $(p=0.002)$, and Bordetella pertussis $(p<0.0001)$ titers were found to be significantly lower in the case group than the control group. There was a significant decline in pneumococcus titers with severity of disease $(p=0.021)$ and a significant association with disease severity for Bordetella pertussis titers $(p=0.014)$ among COVID patients. Levels of AST, procalcitonin, ferritin and D-dimer significantly increased with the disease severity. Discussion: Our study supports the hypothesis that pre-existing immune memory, as monitored using circulating antibodies, acquired from 
childhood vaccinations, or past infections confer some protection against COVID-19. Randomized controlled studies are needed to support a definitive conclusion. 
1 Is There a Link between Pre-Existing Antibodies Acquired Due to Childhood Vaccinations 2 or Past Infections and COVID-19? A Case Control Study

3 Bilge Sumbul ${ }^{1}$, Hilmi Erdem Sumbul ${ }^{2}$, Ramazan Azim Okyay ${ }^{3}$, Erdinç Gülümsek ${ }^{4}$, Ahmet Rıza 4 Şahin $^{5}$, Baris Boral ${ }^{6}$, Burhan Fatih Koçyiğit ${ }^{7 *}$, Mostafa Alfishawy ${ }^{8}$, Jeffrey Gold ${ }^{9}$, ALİ Muhittin 5 Tasdogan 10

$6{ }^{1}$ Bezmialem Vakıf University, Faculty of Medicine, Department of Medical Microbiology, 7 Istanbul, Turkey

$8{ }^{2}$ University of Health Sciences, Adana Health Practice and Research Center, Department of 9 Internal Medicine, Adana, Turkey

$10{ }^{3}$ Kahramanmaraş Sütçü İmam University, Faculty of Medicine, Department of Public Health, 11 Kahramanmaraş, Turkey Internal Medicine, Adana, Turkey

${ }^{5}$ Kahramanmaraş Sütçü İmam University, Faculty of Medicine, Department of Infectious Diseases and Clinical Microbiology, Kahramanmaraş, Turkey

${ }^{6}$ University of Health Sciences, Adana Health Practice and Research Center, Department of Microbiology, Adana, Turkey

7. Kahramanmaraş Sütçü İmam University, Faculty of Medicine, Department of Physical Medicine and Rehabilitation, Kahramanmaraş, Turkey

${ }^{8}$ Infectious Diseases Consultants and Academic Researchers of Egypt (IDCARE), Egypt

${ }^{9}$ World Organization, Watkinsville, Georgia, USA

${ }^{10}$ Hasan Kalyoncu University, Faculty of Health Sciences, Department of Anesthesiology and

Reanimation, Gaziantep, Turkey

Corresponding Author:

Burhan Fatih Koçyiğit ${ }^{7}$

Kahramanmaraş Sütçü İmam Üniversitesi Tıp Fakültesi, Avşar Mah. Batı Çevreyolu Blv. No: 251/A Onikişubat, Kahramanmaraş, 46040, Turkey 


\section{ABSTRACT}

33 Background: There is growing evidence indicating that children are less affected from COVID-

19. Some authors speculate that childhood vaccinations may provide some cross-protection against COVID-19. In this study, our aim was to compare the circulating antibody titers for multiple childhood vaccine antigens, as an indicator of the state of immune memory between patients with COVID-19 and healthy controls, with a specific aim to identify the association between disease severity and antibody titrations which may indicate a protective function related to vaccine or disease induced memory.

Methods: This study is a case-control study including 53 patients with COVID-19 and 40

41 healthy volunteers. COVID-19 severity was divided into three groups: asymptomatic, mild and severe. We measured the same set of antibody titers for vaccine antigens, and a set of biochemical and infection markers, in both the case and control groups.

44 Results: Rubella ( $p=0.003)$, pneumococcus $(p=0.002)$, and Bordetella pertussis $(p<0.0001)$ titers

45 were found to be significantly lower in the case group than the control group. There was a 46 significant decline in pneumococcus titers with severity of disease $(p=0.021)$ and a significant 47 association with disease severity for Bordetella pertussis titers $(p=0.014)$ among COVID 48 patients. Levels of AST, procalcitonin, ferritin and D-dimer significantly increased with the 49 disease severity. 
50 Discussion: Our study supports the hypothesis that pre-existing immune memory, as monitored

51 using circulating antibodies, acquired from childhood vaccinations, or past infections confer

52 some protection against COVID-19. Randomized controlled studies are needed to support a 53 definitive conclusion.

54 
55

56

57

\section{Introduction}

The whole world is struggling to control the 2019 Coronavirus Disease (COVID-19), and facing unacceptable mortality in the hundreds of thousands in many countries (Dong, Du \& Gardner, 2020). Worldwide development of specific vaccines is underway. Even though some are being approved today, it will take many months for them to be produced and distributed to all susceptible people across the world. This window without a clear pathway to protecting those at-risk mandates scientists seek other effective measures to mitigate the severity of disease and reduce the future death toll.

Given the available data indicating that children are generally less likely to be affected by COVID-19, and that those between 6-10 years of age have shown significantly lower mortality and less severe disease (Dong et al., 2020) leads one wonder if the compulsory child vaccination programs practiced in many countries have a role in mitigating COVID disease in that age group. Further, it poses the question, can one or more of these vaccines act as a vehicle for preventing, or modulating, the severity of COVID-19?

In Turkey, where this study was conducted, an expanded childhood immunization program is being implemented by the ministry of health. According to the estimates by the World Health Organization and UNICEF, the coverage of basic childhood vaccines, such as Bacillus Calmette-Guerin (BCG), Tetanusdiphtheria-pertussis, Polio, Measles, Rubella, Hepatitis B, Haemophilus influenzae B and Pneumococcal conjugate vaccines currently range between $88 \%$ and $99 \%$ of children in the country. (WHO \& UNICEF, 2020)

Our group was the first to hypothesize that childhood vaccines provide some level of cross-protection against COVID-19 (Gold, 2020; Okyay et al., 2020). Soon afterwards, several other authors proposed similar hypotheses (Salman \& Salem, 2020; Lyu et al., 2020). We proposed that one or more childhood vaccines, or comparable antibodies from a past infections, may indicate a network of immune memory that can be reactivated to provide some type of cross-protection. It may be adaptive elements, such as the antibodies themselves which recognize coronavirus to some level, or it may be the product of bystander 
activation by weakly recognized antigens that initiate reactivation of memory clones which produce cytokines to drive the process of "trained innate immunity" through tissue level priming of the local

81 response network.

82 The enhancement of innate immune function by priming activation, more focused response and better

83 92 2020).

93

94

95 regulation has been recognized for a number of vaccines (Netea et al., 2016) The primary goal, and major benefit of vaccines is to provide either circulating available effector activity against a specific agent, or a pool of memory cells capable of being activated to provide rapid and lasting protection. A side benefit of many vaccines, particularly live agent vaccines, is the development of lasting trained innate immunity.

In many places in the world scientists are currently testing the BCG vaccine for its ability to provide a level of protection against COVID-19. They postulated the role of the BCG vaccine based on prior research that showed the ability of BCG to protect against unrelated infections. Also, epidemiological studies have shown an increase in COVID-19 prevalence in areas with lower vaccine use (Miller et al.,

Measles vaccine was also proposed as a possible mitigator of COVID-19 disease. Similarities were noted in their cutaneous manifestations (Recalcati, 2020). Further, the measles vaccine has been used as a vector for other coronavirus specific vaccines including Severe Acute Respiratory Syndrome (SARS) and the Middle East Respiratory Syndrome Coronavirus (MERS-CoV). These vaccines were able to induce multifunctional T cell response in a mouse model (Bodmer, 2018).

Studies are needed to further test these hypotheses. We hypothesized that there might be a relationship between the levels of circulating antibodies we can measure, that we believe reflect the memory pools acquired following childhood vaccinations, or past infections, and COVID-19 disease. Therefore, in this study, our purpose was to measure antibody titers in patients with COVID-19, and a matched pool of healthy controls from the same community. This was done with the specific aim of measuring the 
103 association between disease severity and antibody titers as predictors of protection in COVID-19 disease

104 development.

105

106 Materials and Methods

107 This study, planned as a case-control study, was conducted at the Adana City Training and Research

108 Hospital, Internal Medicine and COVID Clinic. Written informed consent of patients and volunteers were 109 obtained, between April 1, 2020 and May 1, 2020. During the study, 53 patients with COVID-19 without 110 co-morbidity, over the age of 18 , and 40 healthy volunteers were included in the study.

\section{Study population}

112 Patients who were diagnosed by their histories, physical examinations, imaging and laboratory findings, 113 and who agreed to enroll in the study, were included. Patients with diabetes mellitus, thyroid disease, 114 hyperlipidemia, kidney failure, heart disease, hematological disease, lung disease, rheumatic disease, 115 presence of malignancy, pregnancy and those who did not agree to participate in the study were excluded. 116 After all patients and healthy volunteers were included in the study, a detailed history was taken, a 117 physical examination was performed, and the age and sex of participants were recorded. The case group 118 was divided into three subgroups according to the severity of the disease: asymptomatic, mild and severe 119 COVID-19 cases.

\section{Laboratory testing}

121 Both oropharyngeal and nasopharyngeal swabs were collected for each patient. The swabs were taken to 122 the laboratory and processed using rapid extraction kits. The samples were assessed using a Roche 123 LightCycler Instrument (Device reference number: 05815916001, Serial number: 11927, Switzerland).

124 They were handled and processed in accordance with cold chain storage conditions. In addition to routine 
125 blood tests for the patients and healthy volunteers included in the study, antibody titers were assessed. For

126 antibody titers, $5 \mathrm{cc}$ blood samples were taken from the patients, the serum part was separated by

127 centrifugation for 10 minutes at 2000 Revolutions Per Minute (RPM). and placed in Eppendorf tubes and

128 stored at $-80^{\circ} \mathrm{C}$ degrees. The hs-Troponin levels of the patients and healthy volunteers included in the

129 study was measured with the UniCel DXI Analyzer (Beckman Coulter; USA). Sodium (Na), potassium

$130(\mathrm{~K})$, calcium (Ca), glucose, alanine aminotransferase (ALT), aspartate aminotransferase (AST), blood

131 urea nitrogen $(\mathrm{BUN})$, creatinine, procalcitonin, sedimentation rate, $\mathrm{C}$ reactive protein $(\mathrm{CRP})$, fibrinogen,

132 troponin, ferritin, D-dimer and whole blood cell levels were measured using an automated Aeroset

133 chemistry analyzer (Abbott, MN, USA) with appropriate Abbott commercial kits.

\section{Pre-existing antibody titers}

135 Pre-existing antibodies to be measured were determined based on the vaccines commonly used in 136 childhood. Serum levels of Measles Virus IgG, Rubella Virus IgG, Mumps Virus IgG, Diphtheria IgG,

137 Bordetella pertussis IgG, Tetanus IgG, Haemophilus influenzae B IgG, were evaluated using Serion 138 ELISA classic (InstitutVirion $\backslash$ Serion GmbH Friedrich-Bergius-Ring 1997076 Würzburg, Germany)

139 brand commercial kit. Serum levels of Varicella-Zoster Virus IgG and Pneumococcus IgG were analyzed 140 using the Testline (TestLine Clinical Diagnostics Krizikova 68612 Brno Czech Republic) brand kit. The 141 titers of antibodies were determined using purified antigens.

142 Levels of $\geq 200, \geq 20, \geq 100, \geq 1, \geq 0.35, \geq 50, \geq 0.50, \geq 1.15$, and $\geq 15$ antibody units were considered as 143 positive for measles, rubella, mumps, pneumococcus, diphtheria, Bordetella pertussis, tetanus, varicella 144 and Haemophilus influenzae B, respectively.

\section{Statistical analysis}

146 Data were expressed as values, percentages and medians (minimum-maximum). In dichotomous 147 variables, the difference between case and control was tested using the Pearson's chi-square test. The 
148 difference between quantitative parameters between case and control was evaluated using the Mann

149 Whitney U test. Disease severity was divided into three groups as asymptomatic, mild and severe. The

150 difference of quantitative parameters among these three groups was evaluated with the Kruskal Wallis

151 test. Post-hoc analysis of Kruskal Wallis test was performed using Dunn test for significant results and

152 false discovery rates were also presented as Benjamini-Hochberg Adjusted p values. Spearman

153 correlation analysis was used to determine whether there was a correlation between antibody titers and

154 other measurement-related biological or biochemical parameters.

\section{Ethical considerations}

156 The study was performed according to the tenets of the Declaration of Helsinki for research involving

157 human subjects. The study was approved by the Ethics Committee of Çukurova University with the date

158 of May 8, 2020 and number 52/99. The study was also approved by the Ministry of Health. Written

159 consent was obtained from the participants before starting the study.

\section{Results}

161 The median age of the case group included in the study was $42(\min =21, \max =87)$, and the median age

162 of the control group was $51.5(\min =25, \max =78)$. The age distributions of both groups were similar $163(p=0.186)$. The gender distribution of the case and control groups were also similar $(p=0.694) ., 52.5 \%$ of 164 the case group, and $56.6 \%$ of the control group were male.

165 When comparing the case and control groups in terms of certain biological or biochemical parameters, it 166 was found that median $\mathrm{Na}, \mathrm{Ca}$, troponin, ferritin levels and lymphocyte and platelet counts were 167 significantly lower in the COVID-19 group. In contrast the median ALT, AST, procalcitonin, CRP, 168 fibrinogen D-dimer levels and sedimentation rate were significantly higher in the COVID-19 group

169 (Table 1). It should be noted that two female patients had troponin values over the $16 \mathrm{ng} / \mathrm{l}$ threshold. None 170 of the controls exceeded this threshold. 
171 We evaluated the differences in the antibody titers to the common vaccine antigens between the two 172 groups. All of the participants, both in case and control groups, were positive for measles titers. Of the 173 case group, all but three patients $(94.3 \%)$, and of the control group all but two people (95.0\%), were 174 positive for rubella. All participants, except for one person in control group, were positive for mumps. Of 175 the case group 22 patients (41.5\%), and of the control group 30 people $(75.0 \%)$, were positive for 176 pneumococcus, and the difference between cases and controls was significant $(p=0.001)$. Of the case 177 group 17 patients (32.1\%), and of the control group 12 people (30.0\%), were positive for diphtheria. Of 178 the case group 10 patients (18.9\%), and of the control group 27 people $(67.5 \%)$, were positive for 179 Bordetella pertussis, the difference between cases and controls was significant $(p<0.0001)$. Of the case 180 group, 38 patients (71.7\%), and of the control group 21 people $(52.5 \%)$, were positive for tetanus. Of the case group 49 patients $(92.5 \%)$, and of the control group 35 people (87.5\%), were positive for Varicella. Of the case group 48 patients $(90.6 \%)$, and of the control group 35 people $(87.5 \%)$, were positive for Haemophilus influenzae B.

When antibody titers were compared between case and control groups, the Rubella, pneumococcus and Bordetella pertussis titers were found significantly lower in the case group than the control group (Table 2).

The case group was divided into three groups according to the severity of the disease: asymptomatic, mild and severe COVID-19 cases. The antibody titers and certain biological or biochemical parameters were compared in these severity groups. The distribution of titers for pneumococcus and Bordetella pertussis were significantly different with the severity of the disease. Pneumococcus titers decreased in a clear fashion as the disease became more severe. However, the difference in Bordetella pertussis titers was not clearly indicative of the severity of disease. Rather, the titer was quite low among those with mild disease impacting the finding of significance (Table 3). The levels of AST, procalcitonin, ferritin and D-dimer appeared to increase with disease severity (Table 4). Post-hoc analysis for results found significant after 
195 the comparison of the aforementioned three groups and false discovery rates were also presented in Table 1965 and Table 6.

197 We observed significant correlations between the antibody titers and biological or biochemical parameters 198 in the COVID-19 group. The mumps titers showed a positive correlation with lymphocyte count 199 (Rho $=0.375, p=0.006)$. The rubella titers showed a negative correlation with the level of $\mathrm{Ca}(\mathrm{Rho}=-0.353$, $200 p=0.015)$. The pneumococcal titers showed a negative correlation with the level of $\mathrm{Ca}(\mathrm{Rho}=-0.296$, $201 p=0.043)$. The Bordetella pertussis titers showed a negative correlation with the sedimentation rate $202(\mathrm{Rho}=-0.498, p=0.001)$ and with the CRP levels (Rho=-0.389, $p=0.010)$. The tetanus titers showed a 203 negative correlation with the level of $\mathrm{D}$-dimer $(\mathrm{Rho}=-0.312, p=0.023)$. The varicella titers showed a 204 negative correlation with the level of ALT (Rho=-0.384, $p=0.005)$, the level of AST (Rho=-0.405, $205 p=0.003)$, procalcitonin $(\mathrm{Rho}=-0.319, p=0.048)$, the sedimentation rate $(\mathrm{Rho}=-0.404, p=0.008)$ and the

206 level of CRP (Rho=-0.378, $p=0.012$ ). The H. influenzae B titers showed a positive correlation with the 207 level of $\mathrm{Na}(\mathrm{Rho}=0.402, p=0.003)$.

\section{Discussion}

209 In this study, we compared a set of randomly chosen healthy controls with a cohort of COVID-19 patients

210 being seen at the same institution and representing the same community. We compared these populations

211 with respect to a number of standard biochemical markers and a rather large set of antibody titers

212 representing common childhood vaccines, or the disease they are designed to provide protection against.

213 This was done to attempt to establish some correlational information that would aid the diagnostic 214 efficacy and prognostic accuracy for COVID-19. We also investigated whether circulating antibodies 215 acquired due to childhood vaccinations, or past infections, appear to be related to a protective effect that 216 is involved in mitigating the severity of the disease.

217 We found that median sodium and calcium levels were lower in the COVID-19 group than the controls.

218 In a meta-analysis of disease biochemistry, it was reported that COVID-19 patients have lower than 
219 normal sodium levels. Further, it was speculated that low body sodium may have resulted in the 220 overexpression of ACE-2. This would increase the binding efficacy of SARS CoV-2 to cells and result in 221 higher disease susceptibility (Luo, Li \& Dai, 2020). Di Filipo et al. (2020) found that hypocalcaemia is 222 highly prevalent in COVID-19 patients. We believe that the assessment of sodium and calcium levels may 223 be of some assistance in diagnosis of COVID-19.

224 Median troponin levels were found lower in the COVID-19 case group in this study. Yet we observed a 225 progressive increase in troponin from asymptomatic to severe cases of COVID-19. This was not, 226 however, statistically significant. Also, two female COVID-19 patients (3.7\% of all patients) had troponin 227 over the $16 \mathrm{ng} / \mathrm{l}$ threshold, while none exceeded this level in control group. There is evidence in the 228 literature that SARS-CoV-2 may cause myocardial injury in some patients (Li et al., 2020; Long et al., 229 2020). Huang et al. (2020) reported 12\% of patients having elevated levels of troponin. Although we found a lower frequency in our study than Huang et al., our findings support the observation of myocardial damage in some COVID -19 patients.

232

233

We found that median ferritin levels were lower in the COVID-19 group than the controls. However severe COVID-19 patients had higher median ferritin levels than did the mild or asymptomatic cases, or the controls (See Table 1 and 4). Mehta et al. (2020) reported high ferritin levels in severe COVID-19 patients and indicated that high ferritin levels may be associated with fatal hypercytokinaemia and the subsequent multiorgan failure. We concluded from previous work and the confirmation from our study that high ferritin levels may be a predictor of poor prognosis in COVID-19.

Lymphocyte and platelet counts were significantly lower in the COVID-19 group. Lymphopenia is a common finding in COVID-19. It has been reported to be associated with severe disease (Terpos et al., 2020). We also observed the lowest median lymphocyte count in severe COVID-19 patients. Xu, Zhou \&Xu (2020) suggested that SARS CoV-2 may reduce platelet production, increase platelet destruction and increase platelet consumption. This would cause thrombocytopenia in COVID-19 patients. Some 
243 authors also speculated that thrombocytopenia is associated with severe COVID-19 disease (Terpos et al.,

244 2020; Lippi, Plebani\& Henry, 2020). In our study, although we did not find a relationship between

245 disease severity and platelet count, our findings support that platelet levels may be low in patients with

246 COVID-19.

247 Median ALT, AST, procalcitonin, CRP, fibrinogen D-dimer levels and sedimentation rate were

248 significantly higher in the COVID-19 group than the control group. All of these biological or biochemical

249 markers had their lowest levels in asymptomatic patients and their highest levels in patients with severe

250 disease. For AST, procalcitonin and D-dimer levels a statistically significant change was observed with

251 the increasing severity of disease. Several authors have reported elevated liver aminotransferase levels in

252 COVID-19 patients. Moreover they found it was associated with disease severity (Guan et al., 2020;

253 Wang et al., 2020; Wang et al., 2020). These findings indicated that SARS-CoV-2 may infect the liver

254 itself and cause cellular damage. Procalcitonin, CRP and sedimentation rate are all inflammatory markers

255 which are expected to increase in infectious diseases (Aringer, 2020). Velavan \& Meyer (2020) in their

256 review, reported studies that find increased procalcitonin and CRP levels in severe COVID-19. Lapić,

257 Rogić \& Plebani M (2020) reported sedimentation rate is also associated with severe COVID-19. In a

258 meta-analysis increased procalcitonin values were reported to be associated with a 5-fold higher risk of

259 severe COVID-19 (Lippi \&Plebani). We concluded that the increase in procalcitonin particularly

260 indicates that bacterial co-infections are probably concurrent with severe COVID-19. Several studies have

261 shown an increase in fibrinogen and D-dimer levels in COVID-19 patients, similar to our observation

262 (Gao et al., 2020; Panigada et al., 2020; Spiezia et al., 2020). This suggests that coagulopathy is frequent

263 in COVID-19 when low platelet levels are also taken into consideration. We also think that the

264 aforementioned biological or biochemical markers may have prognostic values in COVID-19.

265 Our main hypothesis was to test whether pre-existing antibody titers confer protection against COVID-19.

266 Rubella, pneumococcus and Bordetella pertussis titers were found to be significantly lower in the

267 COVID-19 group than the control group. The distribution of titers of pneumococcus and Bordetella 
268 pertussis significantly differed according to the severity of the disease. Pneumococcus titers linearly

269 decreased with the severity of the disease. Bordetella pertussis titers, however, were found to be higher in

270 both asymptomatic and severe cases of COVID-19 and much higher in the controls, but lower in mild

271 cases (Tables 2 and 3). Franklin et al. reported that SARS-CoV-2 spike glycoproteins share structural

272 similarities with the fusion proteins of both measles and mumps viruses and they found $29 \%$ amino acid

273 sequence homology between the macro domains of SARS-CoV-2 and rubella; and concluded that

274 measles, mumps, rubella (MMR) vaccination could improve the outcome of COVID-19 infection

275 (Franklin et al., 2020). Similarly, Gold reported that MMR vaccine appears to confers protection from

276 COVID-19 in a study of the vaccination coverage in different countries around the world and their

277 incidence of COVID-19 disease (Gold, 2020). Although we found a significant difference in COVID-19

278 and control groups in terms of rubella titers, we did not find a significant relationship in the severity of

279 COVID-19 disease based on rubella titer.

280

281

282

283

284

285

286

287

There is evidence of pneumococcus and Bordetella pertussis co-infection in COVID-19 patients (Kozak et al., 2020; Zhu et al., 2020). Zhu et al. reported that 59.5\% of COVID-19 patients were infected with pneumococcus. Further a study published in September, 2020 reported a potential cross-reactivity between SARS-CoV-2 proteins and the pneumococcal proteins (Root-Bernstein, 2020). This may explain the lower pneumococcus titers in severe COVID-19 patients found in our study. We found no relation with Bordetella pertussis titer levels and the severity of the disease. However, the rate of individuals with positive IgG was significantly lower in the COVID-19 group as compared to the controls.

With our findings, we cannot definitively say that a certain type of antibody interacts with SARS-CoV-2 and creates a neutralizing effect and cross protection. The antibody levels found in our study only show traces of previous infections or active immunization by vaccination. Our findings may be interpreted with the concept of trained immunity as an alternative mechanism of protection. Trained immunity can be described as "an innate immune memory program induced by certain infections or vaccinations" (Netea \& van der Meer, 2017). Although a recent study has found a relationship between MMR vaccination and 
293 COVID-19 severity using mumps titers as a proxy (Gold et al., 2020), it was not possible to verify this

294 with our study, since we used alternate methodology. Live pertussis vaccine has been reported to provide 295 non-specific immune responses in mice models, however this effect waned after the vaccine was 296 inactivated by heat (Cauchi \& Locht., 2018). In Turkey, inactive tetanus-diphtheria-pertussis vaccines are 297 given simultaneously. In our study, a significant difference was found with Pertussis antibody titers-, but 298 not with tetanus or diphtheria antibody titers- between the control group and the COVID-19 group. Also, 299 Bordetella pertussis titers were higher in asymptomatic and severe cases as compared to mild cases, 300 which indicates that Bordetella pertussis antibodies did not directly affect disease severity. This suggests 301 that the presumed protection could possibly be due to a silent Pertussis infection, which may induce 302 trained immunity.

303 We have also observed some significant correlations with antibody titers with certain biological or 304 biochemical markers. Mumps titers showed a positive correlation with lymphocyte counts. Rubella and 305 Pneumococcus titers showed a negative correlation with calcium levels. Bordetella pertussis titers showed 306 negative correlations with sedimentation and CRP levels. Tetanus titers showed a negative correlation 307 with D-dimer levels. Varicella titers showed negative correlations with ALT, AST, procalcitonin, 308 sedimentation and CRP levels. H. influenzae B titers showed a positive correlation with sodium levels.

309 These findings demonstrate that multiple different vaccines or past infections may provide some level of 310 protection against COVID-19 either in the form of weakly cross-reactive antibodies, or by providing weakly cross-reactive reactivation of the adaptive memory system and production of cytokines that prime, arm and regulate tissue level innate immunity which retards coronavirus replication and spread in the body with a salutary effect on the development of more severe disease.

314 Our study has some limitations. The sample sizes of both case and control groups were small.

315 Recruitment of healthy controls was difficult and costly in the pandemic era. Therefore, there was an 316 imbalance in case and control numbers. The titrations of antibody for some of the childhood vaccines 317 commonly delivered (Hepatitis A, Hepatitis B and BCG and polio) were not included in the study. Also, 
318 it should be noted that we did not investigate the vaccination history of patients. Thus, the antibodies

319 measured are likely to be due to natural infection as well as vaccination. Nonetheless, to the best of our

320 knowledge, our study was the first to measure pre-existing antibody titers and compare them with healthy

321 individuals. In addition, titers of nine major childhood vaccines were measured in our study.

322 In conclusion, we presented the biological or biochemical markers that changed in COVID-19 patients as

323 compared to healthy controls. We discussed how these markers change according to the severity of

324 COVID-19 disease. We observed that rubella, Bordetella pertussis and pneumococcus titers were lower in

325 COVID-19 patients than in controls. We observed significant correlations between some of the antibody

326 titers and biological or biochemical markers. Our findings support the hypothesis that circulating

327 antibodies indicate some level of protection against COVID-19 that is associated with the memory pool

328 generated by childhood vaccines (or the diseases that they are designed to protect against). Prospective

329 randomized controlled studies are recommended to reach a definitive conclusion.

\section{Acknowledgement}

331 We thank Dr. Hurrem Cebeci and Rene A. Aguinada for sharing their observations. We thank Dr. Adem

332 Doğaner for his contribution in post-hoc anlayses in statistics. We also thank Dr. David J. Hurley for his

333 meticulous contribution in language editing and revising the manuscript with the context of trained

334 immunity.

\section{REFERENCES}

336

337

338

339
Aringer M. 2020. Inflammatory markers in systemic lupus erythematosus. Journal of Autoimmunity 110:102374. Doi: 10.1016/j.jaut.2019.102374.

Bodmer BS, Fiedler AH, Hanauer JRH, Prüfer S, Mühlebach MD. 2018. Live-attenuated bivalent measles virus-derived vaccines targeting Middle East respiratory syndrome coronavirus induce robust and 
340 multifunctional $\mathrm{T}$ cell responses against both viruses in an appropriate mouse model. Virology 521:99-

341 107. Doi: 10.1016/j.virol.2018.05.028

342 Cauchi S, Locht C. 2018. Non-specific Effects of Live Attenuated Pertussis Vaccine Against

343 Heterologous Infectious and Inflammatory Diseases. Front Immunol. 9:2872. Doi:

$344 \quad 10.3389 /$ fimmu.2018.02872.

345 Di Filippo L, Formenti AM, Rovere-Querini P, Carlucci M, Conte C, Ciceri F, Zangrillo A, Giustina A.

346 2020. Hypocalcemia is highly prevalent and predicts hospitalization in patients with COVID-19.

347 Endocrine 68(3):475-478. Doi: 10.1007/s12020-020-02383-5.

348 Dong E, Du H, Gardner L. 2020.An interactive web-based dashboard to track COVID-19 in real time.The

349 Lancet Infectious Diseases 20(5):533-534. Doi: 10.1016/S1473-3099(20)30120-1.

350 Dong Y, Mo X, Hu Y, Qi X, Jiang F, Jiang Z, Tonga S. 2020. Epidemiological Characteristics of 2143

351 Pediatric Patients With 2019 Coronavirus Disease in China. Pediatricspii: e20200702. Doi:

$352 \quad 10.1542 /$ peds.2020-0702.

353 Faul F, Erdfelder E, Lang AG, Buchner A. 2007. G*Power 3: a flexible statistical power analysis program

354 for the social, behavioral, and biomedical sciences. Behavior Research Methods39(2):175-191. Doi:

$35510.3758 / \mathrm{bf} 03193146$.

356 Franklin R, Young A, Neumann B, Fernandez R, Joannides A, Reyahi A, Modis Y. 2020. Homologous

357 protein domains in SARS-CoV-2 and measles, mumps and rubella viruses: preliminary evidence that

358 MMR vaccine might provide protection against COVID-19. Medrxiv Preprint.Doi:

359 10.1101/2020.04.10.20053207.

360 Gao Y, Li T, Han M, Li X, Wu D, Xu Y, Zhu Y, Liu Y, Wang X, Wang L. 2020. Diagnostic utility of

361 clinical laboratory data determinations for patients with the severe COVID-19.Journal of Medical

362 Virology 92(7):791-796. Doi: 10.1002/jmv.25770.

Peer] reviewing PDF | (2020:09:53234:1:0:NEW 30 Dec 2020) 
363 Gold J. 2020. MMR Vaccine Appears to Confer Strong Protection from COVID-19: Few Deaths from

364 SARS-CoV-2 in Highly Vaccinated Populations. ResearchGate Preprint.Doi:

365 10.13140/RG.2.2.32128.25607.

366 Gold JE, Baumgartl WH, Okyay RA, Licht WE, Fidel PL Jr, Noverr MC, Tilley LP, Hurley DJ, Rada B, 367 Ashford JW. 2020. Analysis of Measles-Mumps-Rubella (MMR) Titers of Recovered COVID-19 368 Patients. mBio. 11(6):e02628-20. Doi: 10.1128/mBio.02628-20.

369 Guan GW, Gao L, Wang JW, Wen XJ, Mao TH, Peng SW, Zhang T, Chen XM, Lu FM. 2020. Exploring 370 the Mechanism of Liver Enzyme Abnormalities in Patients With Novel Coronavirus-Infected Pneumonia. 371 Zhonghua Gan Zang Bing Za Zhi 28(2):100-106. Doi: 10.3760/cma.j.issn.1007-3418.2020.02.002.

372 Huang C, Wang Y, Li X, Ren L, Zhao J, Hu Y, Zhang L, Fan G, Xu J, Gu X, Cheng Z, Yu T, Xia J, Wei 373 Y, Wu W, Xie X, Yin W, Li H, Liu M, Xiao Y, Gao H, Guo L, Xie J, Wang G, Jiang R, Gao Z, Jin Q, 374 Wang J, Cao B. 2020. Clinical features of patients infected with 2019 novel coronavirus in Wuhan, 375 China. Lancet 395(10223):497-506. Doi: 10.1016/S0140-6736(20)30183-5.

376 Kozak R, Prost K, Yip L, Williams V, Leis JA, Mubareka S. 2020. Severity of Coronavirus Respiratory 377 Tract Infections in Adults Admitted to Acute Care in Toronto, Ontario. Journal of Clinical 378 Virology 126:104338. Doi: 10.1016/j.jcv.2020.104338.

379 Lapić I, Rogić D, Plebani M. 2020. Erythrocyte sedimentation rate is associated with severe coronavirus 380 disease 2019 (COVID-19): a pooled analysis. Clinical Chemistry and Laboratory Medicine 58(7):1146381 1148. Doi: 10.1515/cclm-2020-0620.

382 Li JW, Han TW, Woodward M, Anderson CS, Zhou H, Chen YD, Neal B. 2020. The impact of 2019 383 novel coronavirus on heart injury: A Systematic review and Meta-analysis. Progress in 384 CardiovascularDiseases S0033-0620(20)30080-30083. Doi: 10.1016/j.pcad.2020.04.008. 
385 Lippi G, Plebani M, Henry BM. 2020. Thrombocytopenia is associated with severe coronavirus disease 3862019 (COVID-19) infections: A meta-analysis. Clinica Chimica Acta; International Journal of Clinical 387 Chemistry506:145-8. Doi: 10.1016/j.cca.2020.03.022.

388 Lippi G, Plebani M. 2020. Procalcitonin in patients with severe coronavirus disease 2019 (COVID-19): A 389 meta-analysis. Clinica Chimica Acta; International Journal of Clinical Chemistry 505:190-191. Doi: 390 10.1016/j.cca.2020.03.004.

391 Long B, Brady WJ, Koyfman A, Gottlieb M. 2020. Cardiovascular complications in COVID-19. The 392 American Journal of Emergency Medicine 38(7):1504-1507. Doi: 10.1016/j.ajem.2020.04.048.

393

394

395

396

397

398

399

400

401

402 403

404

405

406

407

Luo Y, Li Y, Dai J. 2020. Low blood sodium increases risk and severity of COVID-19 : a systematic review, meta-analysis and retrospective cohort study. Medrxiv Preprint.Doi: 10.1101/2020.05.18.20102509.

Lyu J, Miao T, Dong J, Cao R, Li Y, Chen Q. 2020. Reflection on lower rates of COVID-19 in children: Does childhood immunizations offer unexpected protection? Medical Hypotheses 143:109842. Doi: 10.1016/j.mehy.2020.109842.

Mehta P, McAuley DF, Brown M, Sanchez E, Tattersall RS, Manson JJ; HLH Across Speciality Collaboration, UK. 2020. COVID-19: consider cytokine storm syndromes and immunosuppression. Lancet 395(10229):1033-1034. Doi: 10.1016/S0140-6736(20)30628-0.

Miller A, Reandelar M, Fasciglione K, Roumenova V, Li Y, Otazu GH. 2020. Correlation between universal BCG vaccination policy and reduced morbidity and mortality for COVID-19: an epidemiological study. MedRxivpp: 2020.03.24.20042937. Doi: 10.1101/2020.03.24.20042937.

Netea MG, Joosten LA, Latz E, Mills KH, Natoli G, Stunnenberg HG, O'Neill LA, Xavier RJ. 2016.

Trained immunity: A program of innate immune memory in health and disease. Science.

352(6284):aaf1098. Doi: 10.1126/science.aaf1098. 
408 Netea MG, van der Meer JW. 2017. Trained Immunity: An Ancient Way of Remembering. Cell Host 409 Microbe. 21(3):297-300. Doi: 10.1016/j.chom.2017.02.003.

410 Okyay R, Sahin A, Aguinada R, Tasdogan M. 2020. Why are Children Less Affected by COVID-19 ? 411 Could there be an Overlooked Bacterial Co-Infection?. Eurasian Journal Of Medicine And Oncology 412 4(1):104-105. Doi: 10.14744/ejmo.2020.40743.

413 Panigada M, Bottino N, Tagliabue P, Grasselli G, Novembrino C, Chantarangkul V, Pesenti A, Peyvandi 414 F, Tripodi A. 2020. Hypercoagulability of COVID-19 patients in Intensive Care Unit. A Report of 415 Thromboelastography Findings and other Parameters of Hemostasis.Journal of Thrombosis and 416 Haemostasis 18(7):1738-1742.Doi: 10.1111/jth.14850.

417 Recalcati S. 2020. Cutaneous manifestations in COVID-19: a first perspective. Journal of the European 418 Academy of Dermatology and Venereology 34(5):e212-e213. Doi: 10.1111/jdv.16387.

419 Root-Bernstein R. 2020. Possible Cross-Reactivity between SARS-CoV-2 Proteins, CRM197 and 420 Proteins in Pneumococcal Vaccines May Protect Against Symptomatic SARS-CoV-2 Disease and Death. 421 Vaccines (Basel). 8(4):559. Doi: 10.3390/vaccines8040559.

422 Salman S, Salem ML. 2020. Routine childhood immunization may protect against COVID-19. Medical 423 Hypotheses 140:109689. Doi: 10.1016/j.mehy.2020.109689.

424 Spiezia L, Boscolo A, Poletto F, Cerruti L, Tiberio I, Campello E, Navalesi P, Simioni P. 2020. COVID425 19-Related Severe Hypercoagulability in Patients Admitted to Intensive Care Unit for Acute Respiratory 426 Failure. Thrombosis and Haemostasis 120(6):998-1000. Doi: 10.1055/s-0040-1710018.

427 Terpos E, Ntanasis-Stathopoulos I, Elalamy I, Kastritis E, Sergentanis TN, Politou M, Psaltopoulou T, 428 Gerotziafas G, Dimopoulos MA. 2020. Hematological findings and complications of COVID-19. 429 American Journal of Hematology95(7):834-847. Doi: 10.1002/ajh.25829. 
430 Velavan TP, Meyer CG. 2020. Mild versus severe COVID-19: Laboratory markers. 431 International Journal of Iinfectious Diseases 95:304-307. Doi: 10.1016/j.ijid.2020.04.061.

432 Wang Q, Zhao H, Liu LG, Wang YB, Zhang T, Li MH, Xu YL, Gao GJ, Xiong HF, Fan Y, Cao Y, Ding

433 R, Wang JJ, Cheng C, Xie W. 2020. Pattern of liver injury in adult patients with COVID-19: a 434 retrospective analysis of 105 patients. Military Medical Research 7(1):28. Doi: 10.1186/s40779-020435 00256-6.

436 Wang Y, Liu S, Liu H, Li W, Lin F, Jiang L, Li X, Xu P, Zhang L, Zhao L, Cao Y, Kang J, Yang J, Li L, 437 Liu X, Li Y, Nie R, Mu J, Lu F, Zhao S, Lu J, Zhao J. 2020. SARS-CoV-2 infection of the liver directly 438 contributes to hepatic impairment in patients with COVID-19. Journal of Hepatology 73(4):807-816. Doi: 439 10.1016/j.jhep.2020.05.002.

440 World Health Organization, UNICEF. 2020. WHO and UNICEF estimates of national immunization 441 coverage. https://www.who.int/immunization/monitoring_surveillance/data/tur.pdf (accessed 25 442 November 2020)

$443 \mathrm{Xu} \mathrm{P}$, Zhou Q, Xu J. 2020. Mechanism of thrombocytopenia in COVID-19 patients.Annals of 444 Hematology99(6):1205-1208. Doi: 10.1007/s00277-020-04019-0.

445 Zhu X, Ge Y, Wu T, Zhao K, Chen Y, Wu B, Zhu F, Zhu B, Cui L. 2020. Co-infection with respiratory 446 pathogens among COVID-2019 cases. Virus Research 285:198005. Doi: 10.1016/j.virusres.2020.198005. 


\section{Table $\mathbf{1}$ (on next page)}

Comparison of clinical parameters between case and control groups

min: minimum; max: maximum 


\begin{tabular}{|c|c|c|c|}
\hline $\begin{array}{l}\text { Biological or } \\
\text { biochemical } \\
\text { parameters }\end{array}$ & $\begin{array}{c}\text { Case group } \\
\text { [Median (min-max)] }\end{array}$ & $\begin{array}{c}\text { Control group } \\
{[\text { Median (min-max)] }}\end{array}$ & $\mathbf{p}$ \\
\hline Sodium & $138.00(129.00-143.00)$ & $140.00(135.50-143.20)$ & $<0.0001$ \\
\hline Potassium & $4.29(3.57-4.92)$ & $4.37(3.89-5.18)$ & 0.179 \\
\hline Calcium & $9.00(8.30-11.90)$ & $9.50(8.50-11.50)$ & 0.013 \\
\hline Glucose & $101.00(68.00-346.00)$ & $102.00(75.00-377.00)$ & 0.497 \\
\hline ALT & $21.00(6.00-71.00)$ & $17.10(7.50-62.80)$ & 0.007 \\
\hline AST & $28.00(15.00-86.00)$ & $21.50(12.50-76.60)$ & $<0.0001$ \\
\hline Urea & $28.00(11.00-115.00)$ & $32.80(16.60-55.00)$ & 0.072 \\
\hline Creatinin & $0.75(0.36-2.12)$ & $0.76(0.46-1.59)$ & 0.776 \\
\hline Procalcitonin & $0.05(0.03-50.00)$ & $0.03(0.01-0.05)$ & $<0.0001$ \\
\hline Sedimentation & $36.50(13.00-120.00)$ & $6.50(1.00-11.00)$ & $<0.0001$ \\
\hline $\mathrm{C}$ reactive protein & $13.30(1.45-223.00)$ & $0.40(0.00-1.35)$ & $<0.0001$ \\
\hline Fibrinogen & 348.42 (115.00-900.00) & $236.50(178.00-344.00)$ & $<0.0001$ \\
\hline Troponin & $4.00(1.00-176.00)$ & $10.00(2.00-13.00)$ & 0.003 \\
\hline Ferritin & $68.00(10.00-2714.00)$ & $239.00(167.00-356.00)$ & $<0.0001$ \\
\hline D-dimer & $472.00(136.00-6950.00)$ & $319.00(237.00-389.00)$ & $<0.0001$ \\
\hline WBC & $6.00(3.20-12.80)$ & $6.00(3.50-9.10)$ & 0.855 \\
\hline Neutrophile & $4.00(1.50-9.00)$ & $3.25(2.00-6.20)$ & 0.091 \\
\hline Lymhocyte & $1.50(0.40-2.40)$ & $2.10(1.20-3.80)$ & $<0.0001$ \\
\hline Monocyte & $0.60(0.20-1.60)$ & $0.60(0.30-1.00)$ & 0.987 \\
\hline Eosinophil & $0.20(0.10-0.60)$ & $0.20(0.00-0.80)$ & 0.261 \\
\hline Hemoglobin & $13.50(8.80-16.00)$ & $13.55(10.40-16.50)$ & 0.416 \\
\hline Plateletes & $205.00(111.00-393.000)$ & $243.00(95.00-485.00)$ & 0.014 \\
\hline
\end{tabular}




\section{Table 2 (on next page)}

Comparison of pre-existing antibody titers between case and control groups min: minimum; max: maximum 
1

\begin{tabular}{|l|c|c|c|}
\hline Antibody titers & $\begin{array}{c}\text { Case group } \\
{[\text { Median (min-max)] }}\end{array}$ & $\begin{array}{c}\text { Control group } \\
{[\text { Median (min-max)] }}\end{array}$ & p \\
\hline Measles Ig G titers & $9632.50(263.60-453221.00)$ & $6919.75(201.60-38133.00)$ & 0.207 \\
\hline Rubella Ig G titers & $\mathbf{9 5 . 1 0}(\mathbf{1 . 3 0 - 3 0 0 . 9 0 )}$ & $\mathbf{1 5 9 . 3 0 ( 1 7 . 8 0 - 1 8 3 3 . 4 0 )}$ & $\mathbf{0 . 0 0 3}$ \\
\hline Mumps Ig G titers & $194.00(291.40-9445.30)$ & $986.90(62.20-4177.30)$ & 0.251 \\
\hline Pneumococcus Ig G titers & $\mathbf{0 . 7 9}(\mathbf{0 . 1 6 - 9 . 5 3 )}$ & $\mathbf{2 . 3 0}(\mathbf{0 . 0 8}-\mathbf{1 0 . 0 3})$ & $\mathbf{0 . 0 0 2}$ \\
\hline DiphtheriaIg G titers & $0.23(0.01-1.38)$ & $0.19(0.03-1.77)$ & 0.895 \\
\hline B. PertussisIg G titers & $\mathbf{2 0 . 5 0}(\mathbf{4 . 5 0 - 5 1 1 . 2 0})$ & $\mathbf{7 8 . 3 5 ( 1 . 7 0 - 6 9 3 . 5 0 )}$ & $<\mathbf{0 . 0 0 0 1}$ \\
\hline TetanusIg G titers & $1.20(0.00-9.70)$ & $0.55(0.00-24.30)$ & 0.489 \\
\hline Varicella Ig G titers & $2.95(0.66-6.28)$ & $2.92(0.47-5.77)$ & 0.813 \\
\hline H. influenza BIg G titers & $68.40(5.00-1522.60)$ & $51.55(7.00-407.50)$ & 0.055 \\
\hline
\end{tabular}

2

3 


\section{Table 3 (on next page)}

Comparison of pre-existing antibody titers in terms of disease severity

min: minimum; max: maximum 
1

\begin{tabular}{|c|c|c|c|c|}
\hline Antibody titers & $\begin{array}{l}\text { Asymptomatic cases } \\
\text { [Median (min-max)] }\end{array}$ & $\begin{array}{c}\text { Mild cases } \\
\text { [Median (min-max)] }\end{array}$ & $\begin{array}{c}\text { Severe cases } \\
{[\text { Median (min-max)] }}\end{array}$ & $\mathbf{p}$ \\
\hline Measles Ig G titers & $\begin{array}{c}3996.90(263.60- \\
39643.00)\end{array}$ & $\begin{array}{c}10577.00(684.00- \\
453211.00)\end{array}$ & $\begin{array}{c}6762.60(1462.80- \\
38254.00)\end{array}$ & 0.314 \\
\hline Rubella Ig G titers & $79.15(29.50-300.90)$ & $108.20(1.30-217.50)$ & $95.05(29.00-202.20)$ & 0.897 \\
\hline Mumps Ig G titers & $\begin{array}{l}960.80(402.80- \\
6060.30)\end{array}$ & $\begin{array}{c}1252.30(291.40- \\
9445.30)\end{array}$ & $\begin{array}{c}1213.40(361.00- \\
3493.80)\end{array}$ & 0.820 \\
\hline Pneumococcus Ig G titers & $2.01(0.21-7.38)$ & $0.50(0.17-9.53)$ & $0.45(0.16-1.28)$ & 0.021 \\
\hline DiphtheriaIg G titers & $0.38(0.03-1.22)$ & $0.18(0.02-1.38)$ & $0.18(0.01-0.97)$ & 0.551 \\
\hline B. Pertussis Ig G titers & $37.95(12.90-85.30)$ & $17.00(4.50-511.20)$ & $36.15(12.80-66.70)$ & 0.014 \\
\hline TetanusIg $\mathrm{G}$ titers & $1.65(0.00-5.40)$ & $1.10(0.00-9.70)$ & $1.40(0.00-6.30)$ & 0.740 \\
\hline Varicella Ig G titers & $3.84(1.34-6.28)$ & $2.92(1.10-5.09)$ & $2.57(0.66-4.86)$ & 0.237 \\
\hline H. influenza BIg G titers & $62.25(17.30-299.00)$ & $70.30(5.00-965.60)$ & $53.50(9.40-1522.60)$ & 0.993 \\
\hline
\end{tabular}

2 
Table 4 (on next page)

Comparison of clinical parameters in terms of disease severity

min: minimum; max: maximum 
1

\begin{tabular}{|c|c|c|c|c|}
\hline $\begin{array}{l}\text { Biological or } \\
\text { biochemical } \\
\text { parameters }\end{array}$ & $\begin{array}{l}\text { Asymptomatic cases } \\
{[\text { Median (min-max)] }}\end{array}$ & $\begin{array}{c}\text { Mild cases } \\
\text { [Median (min-max)] }\end{array}$ & $\begin{array}{c}\text { Severe cases } \\
{[\text { Median }(\min -m a x)]}\end{array}$ & $\mathbf{p}$ \\
\hline Sodium & $138.00(136.00-141.00)$ & $138.00(129.00-142.00)$ & $137.50(132.00-143.00)$ & 0.593 \\
\hline Potassium & $4.21(3.87-4.61)$ & $4.31(3.57-4.79)$ & $4.36(3.64-4.92)$ & 0.616 \\
\hline Calcium & $8.90(8.30-9.80)$ & $9.10(8.40-10.00)$ & $9.05(8.30-11.90)$ & 0.420 \\
\hline Glucose & $102.50(79.00-221.00)$ & $99.00(68.00-346.00)$ & $104.50(96.00-153.00)$ & 0.470 \\
\hline ALT & $20.00(11.00-38.00)$ & $21.00(6.00-65.00)$ & $36.50(16.00-71.00)$ & 0.237 \\
\hline AST & $24.00(20.00-32.00)$ & $25.00(15.00-86.00)$ & $44.00(33.00-73.00)$ & $<0.0001$ \\
\hline Urea & $27.00(16.00-43.00)$ & $27.00(12.00-115.00)$ & $35.00(11.00-44.00)$ & 0.428 \\
\hline Creatinin & $0.72(0.40-1.10)$ & $0.74(0.36-2.12)$ & $0.78(0.62-1.05)$ & 0.579 \\
\hline Procalcitonin & $0.05(0.03-0.10)$ & $0.05(0.03-2.00)$ & $12.00(2.00-50.00)$ & $<0.0001$ \\
\hline Sedimentation & $29.00(19.00-65.00)$ & $38.50(13.00-120.00)$ & $79.00(23.00-111.00)$ & 0.117 \\
\hline $\mathrm{C}$ reactive protein & $4.94(1.49-58.40)$ & $14.10(1.45-195.00)$ & $77.70(2.50-223.00)$ & 0.068 \\
\hline Fibrinogen & $316.66(199.60-378.89)$ & $358.66(167.28-694.00)$ & $507.66(115.00-900.00)$ & 0.388 \\
\hline Troponin & $3.00(2.00-8.00)$ & $4.00(1.00-176.00)$ & $6.50(2.00-22.00)$ & 0.245 \\
\hline Ferritin & $29.35(10.00-111.60)$ & $104.30(16.30-1420.10)$ & $365.00(33.20-2714.00)$ & 0.022 \\
\hline D-dimer & $338.50(136.00-1740.00)$ & $440.00(160.00-6950.00)$ & $1134.00(472.00-3760.00)$ & 0.017 \\
\hline WBC & $5.65(3.20-7.30)$ & $6.10(3.20-10.40)$ & $6.80(3.30-12.80)$ & 0.333 \\
\hline Neutrophile & $3.30(1.50-5.10)$ & $3.90(1.70-8.70)$ & $4.55(2.10-9.00)$ & 0.354 \\
\hline Lymhocyte & $1.40(0.80-2.00)$ & $1.60(0.40-2.30)$ & $1.10(0.90-2.40)$ & 0.561 \\
\hline Monocyte & $0.60(0.50-0.80)$ & $0.60(0.30-1.00)$ & $0.50(0.30-1.60)$ & 0.887 \\
\hline Eosinophil & $0.30(0.10-0.60)$ & $0.20(0.10-0.60)$ & $0.15(0.10-0.30)$ & 0.330 \\
\hline Hemoglobin & $13.30(11.00-15.80)$ & $13.60(10.20-16.00)$ & $13.00(8.80-15.50)$ & 0.771 \\
\hline Plateletes & $183.50(135.00-313.00)$ & $213.00(127.00-393.00)$ & $198.00(111.00-380.00)$ & 0.566 \\
\hline
\end{tabular}

2 


\section{Table 5 (on next page)}

Post-hoc analysis of significant results observed in biochemical parameters when comparing disease severity groups

${ }^{a} p$ value obtained with Dunn Test ${ }^{b}$ Benjamini-Hochberg Adjusted $p$ value ${ }^{c}$ Kruskall Wallis test 
2

\begin{tabular}{|c|c|c|c|c|c|c|c|}
\hline \multirow[t]{2}{*}{$\begin{array}{l}\text { Biochemical } \\
\text { parameters }\end{array}$} & \multicolumn{2}{|c|}{$\begin{array}{c}\text { Asymptomatic cases- } \\
\text { Mild cases } \\
(1-2)\end{array}$} & \multicolumn{2}{|c|}{$\begin{array}{c}\text { Asymptomatic cases - } \\
\text { Severe cases } \\
(1-3)\end{array}$} & \multicolumn{2}{|c|}{$\begin{array}{c}\text { Mild cases } \\
\text {-Severe cases } \\
(2-3)\end{array}$} & \multirow{2}{*}{$\begin{array}{c}\mathbf{K W} \mathbf{W}^{\mathbf{c}} \\
\mathbf{p}\end{array}$} \\
\hline & $\mathbf{p}^{\mathbf{a}}$ & FDR $_{\text {BH }}{ }^{b}$ & $\mathbf{p}^{\mathrm{a}}$ & FDR $_{\text {BH }}$ & $\mathbf{p}^{\mathbf{a}}$ & FDR $_{\text {BH }}$ & \\
\hline AST & 0.145 & 0.145 & 0.0001 & 0.0003 & 0.001 & 0.0015 & $<0.0001$ \\
\hline Procalcitonin & 0.743 & 0.743 & 0.001 & 0.0015 & 0.0001 & 0.0003 & $<0.0001$ \\
\hline Ferritin & 0.010 & 0.03 & 0.023 & 0.00345 & 0.598 & 0.598 & 0.022 \\
\hline D-dimer & 0.341 & 0.341 & 0.006 & 0.018 & 0.015 & 0.0225 & 0.017 \\
\hline
\end{tabular}

3

4

5

6

7

8

9 


\section{Table 6 (on next page)}

Post-hoc analysis of significant results observed in antibody titers when comparing disease severity groups

${ }^{a} p$ value obtained with Dunn Test ${ }^{b}$ Benjamini-Hochberg Adjusted $p$ value ${ }^{c}$ Kruskall Wallis test 
2

\begin{tabular}{|l|c|c|c|c|c|c|c|}
\hline $\begin{array}{l}\text { Antibody } \\
\text { titers }\end{array}$ & \multicolumn{2}{|c|}{$\begin{array}{c}\text { Asymptomatic cases- } \\
\text { Mild cases } \\
(\mathbf{1 - 2})\end{array}$} & $\begin{array}{c}\text { Asymptomatic cases - } \\
\text { Severe cases } \\
(\mathbf{1 - 3 )}\end{array}$ & \multicolumn{2}{c|}{$\begin{array}{c}\text { Mild cases } \\
\text {-Severe cases } \\
(\mathbf{2 - 3})\end{array}$} & $\mathbf{K W}^{\mathbf{c}}$ \\
\hline & $\mathbf{p}^{\mathbf{a}}$ & FDR $_{\mathbf{B H}} \mathbf{b}$ & $\mathbf{p}^{\mathbf{a}}$ & $\mathbf{F D R}_{\mathbf{B H}}$ & $\mathbf{p}^{\mathbf{a}}$ & $\mathbf{F D R}_{\mathbf{B H}}$ & $\mathbf{p}$ \\
\hline $\begin{array}{l}\text { Pneumococcus } \\
\text { Ig G titers }\end{array}$ & $\mathbf{0 . 0 1 7}$ & $\mathbf{0 . 0 2 5}$ & $\mathbf{0 . 0 1 1}$ & $\mathbf{0 . 0 3 3}$ & 0.374 & 0.374 & $\mathbf{0 . 0 2 1}$ \\
\hline $\begin{array}{l}\text { B. Pertussis Ig } \\
\text { G titers }\end{array}$ & $\mathbf{0 . 0 0 6}$ & $\mathbf{0 . 0 1 8}$ & 0.459 & 0.459 & 0.109 & 0.163 & $\mathbf{0 . 0 1 4}$ \\
\hline
\end{tabular}

3

4

5

6 